\title{
STUDY ON COPING AMONG PARENTS WITH CHRONIC ILL CHILD
}

\author{
Mera Thomas ${ }^{* 1}$ \\ $*^{1}$ B.Sc. Psychology Student, III year, \\ Yuvakshetra Institute of Management Studies, \\ Ezhakkad, Palakkad, \\ Kerala, 678631.
}

\author{
Sannet Thomas ${ }^{* 2}$ \\ $*^{2}$ Assistant Professor, \\ Department of Psychology, \\ Yuvakshetra Institute of Management Studies, \\ Ezhakkad, Palakkad, \\ Kerala, 678631.
}

Article DOI: https://doi.org/10.36713/epra5343

\begin{abstract}
Coping is the use of cognitive and behavioral strategies to manage the demands of a situation when these are appraised as taxing or exceeding one's resources or to reduce the negative emotions and conflict caused by stress(American Psychological Association). A physical disability is a limitation on a person's physical functioning, mobility, dexterity or stamina. Other physical disabilities include impairments which limit other facets of daily living, such as respiratory disorders, blindness, epilepsy and sleep disorders. A mentally disabled is characterized by below-average intelligence or mental ability and a lack of skills necessary for day-to-day living. People with intellectual disabilities can and do learn new skills, but they learn them more slowly. The study aimed to find the coping of parents with physically or mentally disabled child in different situations or occasions. The sample considered included a total of 35 parents with 18 females and 17 males were selected using purposive sampling. Coping Health Inventory for Parents (McCubbin, Patterson, Cauble, Wilson and Warwick, 1983) was used for data collection. The data was analyzed using frequency distribution, standard deviation and correlation. The result showed that the coping patterns were different based on their gender. The father were having a higher emotional disturbance as compared to that of the mother, they also had an unsatisfactory relationship to the chronically ill-child. Whereas, the mother had a higher level of relationship with the chronically ill-child. The result also showed that there was a significant correlation between the coping patterns of many families in different occasion.
\end{abstract}

KEYWORDS: Coping

\section{INTRODUCTION}

Coping refers to invest one's own conscious effort to solve personal and interpersonal problems, in order to try to master, minimize or tolerate stress and conflict according toWeiten, W. \& Lloyd, M.A. It is the process of spending mental, conscious energy on dealing with problems in life. Lazarus R., Folkman S. and his colleagues describe the coping process as consisting of appraisal, behavior, and reappraisal. Appraisal involves an evaluation of the extent to which a situation is challenging or harmful and an assessment of the internal and external resources available to deal with the situation. Coping behavior follows this appraisal and then a reappraisal is made to determine the extent to which the coping behavior had the desired effect.

\section{Study on coping among parents with} chronic ill child

Qualities of the individual that influence coping include age, gender, socioeconomic status, personality, beliefs and values. Girls and women are more likely than boys and men to seek social support when confronted with stress. Aspects of the situation that affects coping include the extent to which the stressor 
is acute versus chronic in nature, in familiar or novel, is controllable, involves threat as opposed to loss, involves a conflict situation and is interpersonal in nature. For interpersonal situation, the power difference of those involved is another relevant factor. Familial, cultural and social aspects of the environment also influence coping behavior.

Parenting a chronically ill child is a challenge. Having a child with a chronic illness is stressful for any family. Parents of a chronically ill a child are often faced with difficulties and decisions that other parents will never have to face. A major task parent of a chronically ill child face is the responsibilities of helping their child cope with his or her illness.

\section{Definition of key terms}

Coping: Coping is defined as constantly changing cognitive and behavioral efforts to manage specific external and internal demands that are appraised as taxing or exceeding the resource of the person. (Lazarus et al., 1984).

\section{REVIEW OF LITERATURE}

Anderson (1981) conducted a study on the social construction of illness experience: families with a chronically-ill child which examined how parents constructed the illness of a child with chronic sickness. The focus was on how they understood and described their child's illness, and how they managed their interactions with the child. The data was collected were collected by using an ethnographic approach. In addition to obtaining parents accounts, naturally occurring interactions between parents and children were observed and tape recorded. The paper discusses the parent's semantic definition of the 'child as normal'.

Damrosch et al., (1989) conducted a study on self-reported adjustment, chronic sorrow and coping of parents of children with Down syndrome. It analyzed questionnaires from 18 fathers and 22 mothers of children with Down syndrome with an age range from infancy to adulthood (mean age 6.59 yrs.). Fathers depicted their adjustment in terms of steady, gradual recovery, while the majority of mothers reported a peaks-and-valleys, periodic crises pattern. Mothers also reported higher frequencies for chronic sorrows as well as for behavior such as self-lame and expression of negative affect. The study suggests that mothers and fathers in the same family may experience distinct differences in adjustment and coping as parents of a handicapped child.

Deatrick et al., (1990) conducted a study on management behaviors: day- to-day adjustments to childhood chronic conditions. It was conducted to understand how families who have children with chronic conditions make daily adjustments to accommodate the children's special needs, the concept of management behavior is explored. On theoretical level, the adjustments are linked to an emerging conceptual model, family management style (FMS). As such, the management behaviors component of the FMS model is highlighted and developed to guide further clinical exploration and research

Gibson (1986) conducted a study on how parents cope with a child with cystic fibrosis. The convenience sample consisted of 56 parents whose children were diagnosed with $\mathrm{CF}$ and aged 10 years or under. The upper age limit of 10 years was selected to avoid the effects of confounding variables related to the developmental stage of adolescence on family relationships. The parents in this study had provided insight into the challenges that a chronic illness, such as $\mathrm{CF}$, in a child bring to them. As well, they had provided an indication of the resources that have enabled them to manage.

\section{Study on coping among parents with chronic ill child}

McCubbin et al., (1983) conducted a study on CHIP: Coping health inventory for parents: an assessment of parental coping patterns in the care of the chronically ill child. Data were collected on 100 families who have a child with cystic fibrosis; mothers' median age was 35 yrs. and fathers' was 37 yrs. By factor analyzing scaled responses to behavior items on the coping health inventory for parents (CHIP), 3 parental coping patterns emerged. These patterns were validated against criterion measures of improvement in the child's health and adaptive family-life dimensions of cohesiveness, expressiveness, conflict reduction, organization, and control.

\section{Rationale}

After reviewing the literature, it was found that there are no studies that test Coping among parents with chronic ill child based on gender.

\section{METHODS}

\section{Problem}

Is there any coping among parents with chronic ill child based on their gender?

Aim

To find the level of coping among parents with a chronic ill child.

\section{Objective}

To measure a level of coping among parents with chronic ill child.

\section{Variables}

Independent variable: Gender

Dependent variable: Coping 


\section{Hypothesis}

1. There will be no significant difference in coping among parents based on gender.

\section{Research design}

The research study was quantitative in nature and the research adopted standard deviation in coping among parents with chronic ill child

\section{Research sample}

Study on coping among parents with chronic ill child

Purposive sampling method was used for this study. The study sample consisted of 34 people out of which 17 were males and 17 were females. The sample was equally taken from the population by the basis of gender. It has been taken from Kerala. It belonged to different gender, religion, family type, status and different area of residence.

\section{Sampling criteria}

Inclusion criteria:

1. Only those who are willing to participate via online means of communication

2. Only parents with a chronically ill child were considered.

3. Age limit: $30-50$ yrs.

\section{Exclusion criteria}

- Those parents who do not have a chronic ill child.

- Those who are not willing to participate in the

Tools online survey.

The following tool was administered for collecting the required data

- Coping Health Inventory for Parents (CHIP) (McCubbin et al., 1983).

\section{Procedure}

The study was explained to the participants through online and a rapport was build between the participant and the researcher through online. Each participant were individually mentioned about the purpose of the study as well as were informed about the confidentiality of their responses. Then the questionnaires were administered through online mode of communication and the responses were noted. The scoring for the assessment was done and interpreted.

\section{Analysis of data}

The collected data were analyzed using statistical package for social science (SPSS-26). The following statistical tests were carried:

- Mean, Standard Deviation

- Independent sample t-test

Ethical Issue

- Confidentiality of the collected information was maintained throughout the study.

- Collected data were only used for research purpose.

\section{Study on coping among parents with} chronic ill child

\section{RESULT}

\section{Data Analysis and interpretation}

The aim of the study was to find the coping among parents with chronic ill child. The study consisted of 34 parents out of which 17 were males and 17 females. For the purpose of the study the investigator formulated a hypothesis and the results are shown below

Table 1: t-ratio for gender

\begin{tabular}{|c|c|c|c|c|c|c|c|}
\hline Variable & Gender & $\mathbf{N}$ & Mean & SD & $\boldsymbol{t}$ & $\boldsymbol{d}$ & $\begin{array}{c}\text { Sig } \\
\text { value(2- } \\
\text { tailed) }\end{array}$ \\
\hline \multirow{2}{*}{ Coping } & Male & 17 & 68.24 & 11.388 & 0.66 & 32 & 0.948 \\
\cline { 2 - 8 } & Female & 17 & 67.94 & 14.390 & 0.66 & 30.396 & \\
\hline
\end{tabular}

From the above table the average mean of male is 68.24 and that of females is 67.94 which is slightly lower than that of males. By looking at the t-ratio and by comparing the significant value through independent sample t-test coping among parents with chronic ill child is 0.948 which is not significant at the level of 0.05 level of significance.

Thus, from this result the researcher accepts the hypothesis. So there is no significant difference in the level of coping among parents with chronic ill child based on gender.

\section{Major Finding}

- There is no significant difference in coping among parents based on gender.

- Both show same level of significance.

\section{Scope}

- This study can be done on a large population.

\section{Limitations}

- Sample size was small

- Most of the families were not willing to participate 
- Since the study was conducted by online survey the seriousness with which participants Implication answered the questions cannot be verified.

As the result of the study indicates that males have slightly higher level of coping when compared with females. It is clear from this that females have a slightly lower level of coping and they should be focused while using intervention programs. This study can be used for the welfare of the individuals

Study on coping among parents with chronic ill child

\section{CONCLUSION}

The term coping is used when one faces and deals with his or her responsibilities, problems or difficulties. The present study was conducted on 34 parents with equal number of males and females. From the result it is seen that males and females have quite similar level of coping with a chronic ill child. Further studies can be conducted on a large population.

\section{REFERENCES}

1. Anderson J.M. (1981). The social construction of illness experience: Families with a chronically-ill child. Journal of Advanced Nursing. 6: 427-434

2. Damrosch S.P. \& Perry L.A. (1989) Self-reported adjustment, chronic sorrow, and coping of parents of children with Down's syndrome. Nursing Research. 38: 25-29

3. Deatrick J.A. \& Knafl K.A. (1990). Management behaviors: Day-to-day adjustments to childhood chronic conditions. Journal of Pediatric Nursing. 5: 15-22

4. Gibson C.H. (1986). How parents cope with a child with cystic fibrosis. Nursing Papers. 18: 31-45

5. Lazarus, R. S., \& Folkman, S. (1984). Stress, appraisal, and coping. New York: Springer. p.141

6. McCubbin, H., McCubbin, M., Nevin, R., and Cauble, A. (1979). CHIP-Coping Health Inventory for Parents. (Research Instrument). St. Paul, MN; University of Minnesota

7. McCubbin, H., McCubbin, M., Patterson, J., Cauble, A.E., Wilson, L. \& Warwick, P. (1983). Coping health inventory for parents: An assessment of coping patterns in the care of the chronically ill. Journal of Marriage and the Family, 359-370.

8. Skinner, E. A., Edge, K., Altman, J., \& Sherwood, H. (2003). Searching for the structure of coping: A review and critique of category systems for classifying ways of coping. Psychological Bulletin, 129, 216-269.

9. Weiten, W. \& Lloyd, M.A. (2008) Psychology Applied to Modern Life (9th ed.). Wadsworth Cengage Learning 